Editorial

\title{
The Surgical Treatment of Vertigo - A Historical Perspective
}

\author{
Juan Carlos Cisneros Lesser ${ }^{1}$ \\ 1 Otorhinolaryngology and Neurotology, Otolaryngology \\ Department, Instituto Nacional de Rehabilitación, México City, \\ Mexico \\ Int Arch Otorhinolaryngol 2017;21:178.
}

When studying about the evolution of modern day Neurotology, I always find myself amazed with the developments that occurred at the beginning of the 20th century. As early as 1898 , Fedor Krause, considered the father of German neurosurgery, performed the first vestibulocochlear nerve section to treat a patient with severe tinnitus. In 1904, Charles Harrison Frazier, who had trained in Germany and later became one of the biggest influences in the development of early neurosurgery in America, took this idea and carried out the first posterior fossa vestibulocochlear nerve section to treat vertigo in a patient with Ménière's disease. In 1925, Walter Edward Dandy, an American neurosurgeon considered one of the founding fathers of neurosurgery, popularized this technique with good results, but the game changer came in 1931, when a Canadian surgeon, Kenneth G. McKenzie, was able to perform the first selective division of the vestibular nerve. A year after this development, even Dandy, who had already performed around 300 cochleovestibular nerve sections, began to perform vestibular neurectomy with cochlear nerve sparing. He performed 607 procedures of that kind throughout his life, achieving a vertigo control rate as high as $90 \%$, with a mortality rate lower than $1 \%$. What impresses me the most about these earlier years is that all of these surgeries were performed without microscopic assistance, which only began after 1961, when William F. House, considered the father of Neurotology, performed the first microsurgical division of the vestibular nerve through a middle cranial fossa approach.

Competing with the selective vestibular nerve section for the treatment of vertigo in the early $20^{\text {th }}$ century were the many different labyrinthectomy techniques, which originated in 1904 with three English otologists, Lake and Jenkins, from London, and Milligan, from Manchester. Not many years later, a third option appeared: the endolymphatic sac decompression surgery, proposed by Georges Portmann, from Bordeaux, in 1927. The popularity of these less invasive, extradural procedures resulted in a significant reduction in the number of vestibular nerve sections performed later on. It is interesting that almost 100 years have passed since these techniques were first described by those incredibly gifted surgeons, and a verdict of which one is better, or at least better suited for the different clinical situations, is yet a matter of controversy.

In the second half of the 20th century, vestibular surgery continued to evolve, and different approaches were made safer with the use of the operating microscope. Other vestibular pathologies, such as benign paroxysmal positional vertigo, described earlier by Barany in 1921, also gained surgical importance. For instance, in 1974, Richard R. Gacek proposed the first surgical solution for untreatable, recurrent benign paroxysmal positional vertigo: the singular neurectomy. Sixteen years later, in 1990, Parnes and McClure introduced the posterior semicircular canal occlusion. The 1990 were especially interesting, since a completely new pathology emerged in 1998: the superior semicircular canal dehiscence syndrome,

described by Lloyd B. Minor.

It has been an honor to serve as guest editor for this special issue of the International Archives of Otorhinolaryngology. Moreover, I am humbled by the opportunity to work with the authors of this edition, extraordinary neurotologists who selflessly contributed with their time and expertise. In an era in which vestibular implants are being developed, in which endoscopic otologic surgery is gaining terrain and robotics-assisted surgery is more present every day, what is yet to come and how these surgical procedures will evolve will be, without a doubt, extraordinary.

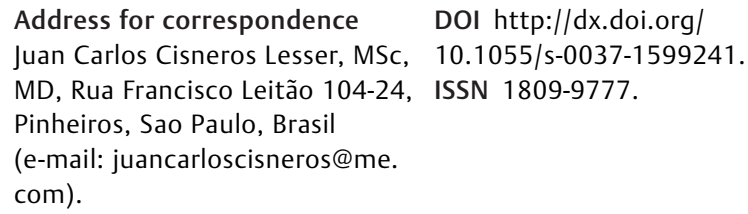

Copyright $\odot 2017$ by Thieme-Revinter Publicações Ltda, Rio de Janeiro, Brazil
License terms

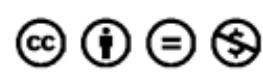

